\title{
Spatial analysis of marine categorical information using indicator kriging applied to georeferenced video mosaics of the deep-sea Håkon Mosby Mud Volcano
}

\author{
Kerstin Jerosch ${ }^{a, *}$, Michael Schlüter $^{a}$, Roland Pesch ${ }^{b}$ \\ ${ }^{a}$ Alfred Wegener Institute for Polar and Marine Research, Am Handelshafen 12, 27570 Bremerhaven, Germany \\ bInstitute for Environmental Science, University of Vechta, Oldenburger Str. 97, 49377 Vechta, Germany
}

\section{A R T I C L E I N F O}

Article history:

Received 2 February 2006

Received in revised form 8 May 2006

Accepted 20 May 2006

Keywords:

Geostatistics

Indicator kriging

Cross-validation

Estimate quality

Mono-parametric habitat maps

Håkon Mosby Mud Volcano

Geographical Information System (GIS)

\begin{abstract}
A B S T R A C T
The exact area calculation of irregularly distributed data is in the focus of all territorial geochemical balancing methods or definition of protection zones. Especially in the deep-sea environment the interpolation of measurements into surfaces represents an important gain of information, because of cost- and time-intensive data acquisition. The geostatistical interpolation method indicator kriging therefore is applied for an accurate mapping of the spatial distribution of benthic communities following a categorical classification scheme at the deep-sea submarine Håkon Mosby Mud Volcano. Georeferenced video mosaics were obtained during several dives by the Remotely Operated Vehicle Victor6000 in a water depth of $1260 \mathrm{~m}$. Mud volcanoes are considered as significant source locations for methane indicated by unique chemoautotrophic communities as Beggiatoa mats and pogonophoran tube worms. For the detection and quantification of their spatial distribution 2840 georeferenced video mosaics were analysed by visual inspection. Polygons, digitised on the georeferenced images within a GIS, build the data basis for geostatistically interpolated mono-parametric surface maps. Indicator kriging is applied to the centroids of the polygons calculating surface maps. The quality assessment of the surface maps is conducted by leave-one-out cross-validation evaluating the fit of the indicator kriging variograms by using statistical mean values. Furthermore, the estimate was evaluated by a validation dataset of the visual inspection of 530 video mosaics not included within the interpolation, thus, proving the interpolated surfaces independently. With regard to both validating mechanisms, we attained satisfying results and we provided each category applied for the identification of biogeochemical habitats with a percentage probability value of occurrence. (c) 2006 Elsevier B.V. All rights reserved.
\end{abstract}

\section{Introduction}

In limnology and marine research, environmental and ecological studies are mainly based on datasets obtained at distinct sites (points) or along track lines gathered during cruises by research vessels. Examples for data collection at distinct sites are water samples acquired for chemical analysis of nutrients or pollutants, plankton samples, or geochemical analysis of sediment cores (Fig. 1). From a geoinformatical perspective these data are of the type point $\left(x_{1}, y_{1}, z_{1}\right)$ or multipoint $\left(x_{1}, y_{1}, z_{1} \ldots z_{n}\right)$. Sampling by bottom trawls or dredges for fishery or petrography are examples for line features $\left(x_{1} \ldots x_{n}\right.$, $\left.y_{1}, \ldots y_{n}, z_{1} \ldots z_{n}\right)$. Only, investigations by multi-beam systems (e.g., applied for bathymetric mapping), by side scan sonar, or video surveys are able to cover strips (polygons) of the seafloor with a width of a few meters to a few hundred meters. Even

\footnotetext{
* Corresponding author.

E-mail address: kjerosch@awi-bremerhaven.de (K. Jerosch).
} 


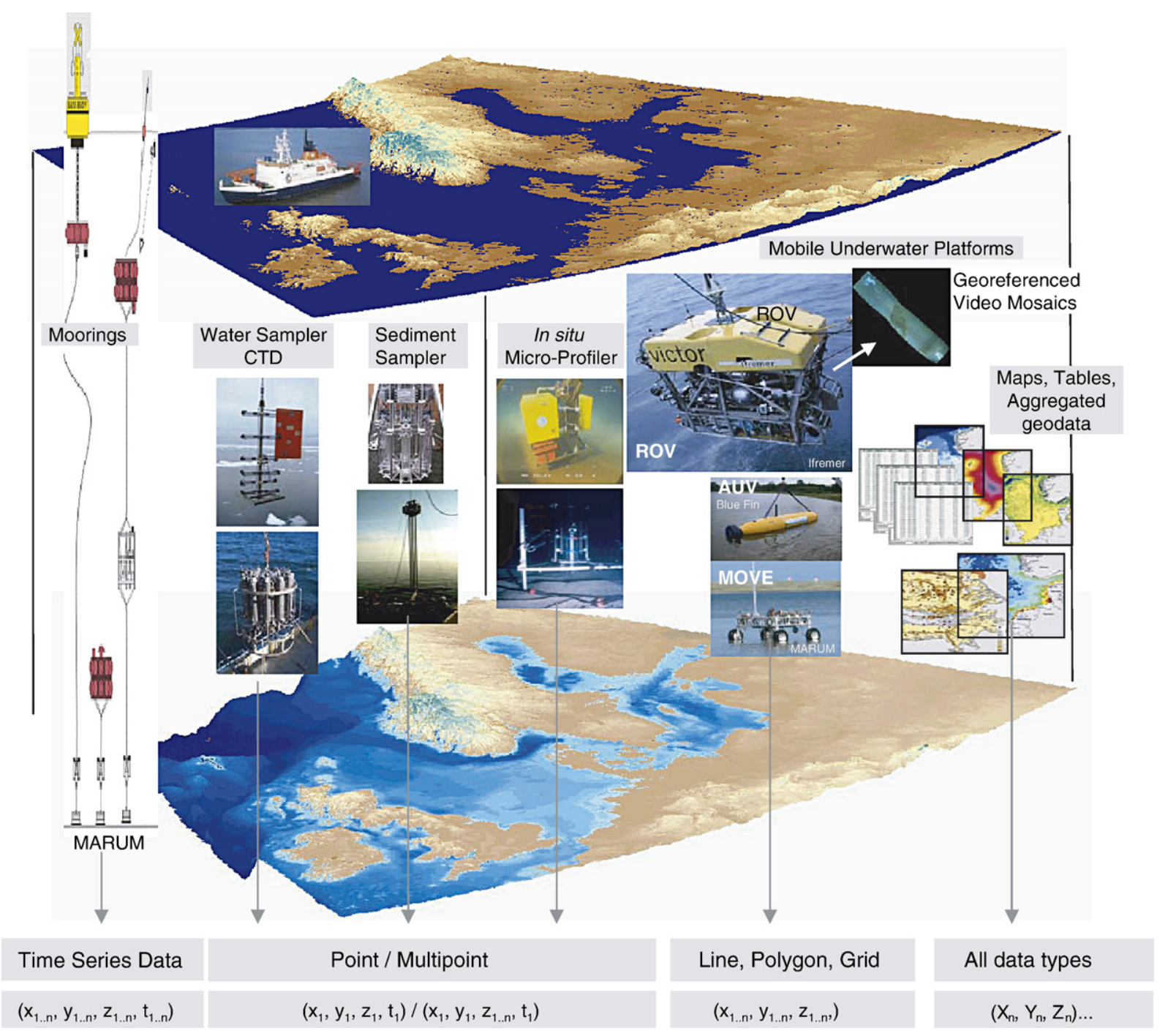

Fig. 1-Examples for sampling methods and data types used in marine research. New techniques as AUVs, ROVs, Crawlers. or moorings (the two latter from MARUM, Univ. Bremen) provide underwater platforms for in situ analysers, acoustic sensors or video systems and for mapping of the seafloor. AUVs are unmanned, self-propelled vehicles designed to carry out measurements along pre-programmed courses and water depths, generally launched and recovered by a surface vessel. ROVs are connected by a cable to a surface vessel and are usually equipped with manipulators (robot arms) for sampling and experiments at the seafloor.

such surveys are unable to provide a dense coverage of larger areas of the coastal zone or the ocean due to time and financial restrictions.

New underwater technologies, as "Autonomous Underwater Vehicles" (AUVs), "Remotely Operated Vehicles" (ROVs) or Crawlers (Fig. 1), operated by offshore industry and a few research institutes, provides a step towards a refined spatial coverage of sampling sites and multi-parameter mapping of the seafloor. These underwater vehicles serve as platforms for in situ analysers (chemical and biological), for acoustic sensors, and underwater imagery by e.g., high resolution video cameras. A major advantage for multi-parameter mapping by ROVs and AUVs is the very accurate navigation by Ultra Short Base Line (USBL) or inertial navigation during the dives.

Due to the large amount of geodata compiled during cruises and dives by ROVs and AUVs marine environmental and ecological studies require concepts for data management of large volumes of heterogeneous datasets. Spatial analysis has to consider and to combine different types of geodata (point, line, and polygon features or time series) and scales. This includes metric scales as measurements of temperature or chemical concentrations, relative scales derived by acoustic mapping techniques, or categorical data associated to the occurrence/ absence of benthic organisms or geological features. Geostatistical techniques for neighbourhood analysis as well as for computation of spatial distributions and maps are applied.

Especially for mapping of geological or biological data, as occurrence of different rocks or sediment types or of benthic organisms and habitats, visual observations by underwater still photography or video imagery are very promising techniques. For example, video surveys by an ROV provides, in contrast to most towed systems, accurately georeferenced 


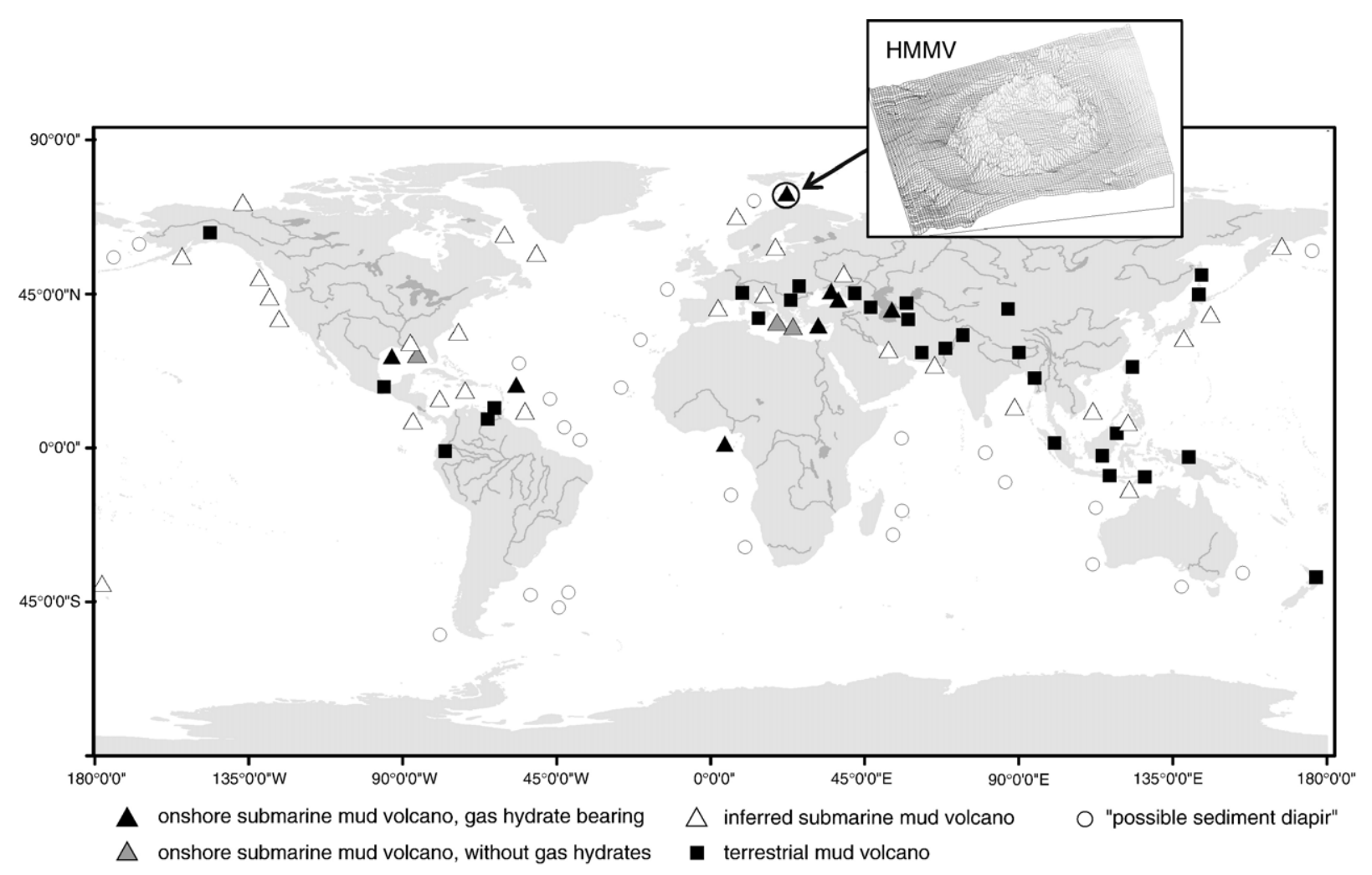

Fig. 2-Worldwide distribution of onshore and offshore submarine mud volcanoes (modified after Milkov, 2000) and geographical location of the HMMV, the only well know mud volcano in polar regions.

images and video sequences. The later can be converted to georeferenced video mosaics (GVM) by mosaicing algorithms (Allais et al., 2004). Visual inspection of GVMs allows to identify specific morphological, geological and biological features and to classify different subregions at the seafloor.

This study is focused to the application of geostatistical techniques and a geographical information system (GIS) to georeferenced video mosaics for computation of spatial distributions of ecological entities at the seafloor. For this purpose video mosaics derived during several dives by the ROV Victor6000 at the Håkon Mosby Mud Volcano (HMMV) were considered. The HMMV is located in a water depth of $1265 \mathrm{~m}$ at the continental margin of the Barents Sea (Northern North Atlantic). The very dense data coverage, compared to the majority of related marine investigations, and the accuracy of navigation data supports the application of variogram analysis and kriging. At marine mud volcanoes seafloor ecology is characterised by specific chemoautotrophic organisms associate to high methane concentrations derived by mud flows ascending from deeper subsurface strata.

\section{Area of investigation and geochemical and ecological background}

Worldwide more than 1700 mud volcanoes (MV) are reported for onshore and offshore environments (Milkov, 2000). It is estimated that more than 10,000 exist in deep marine waters
(Dimitrov, 2002; Fleischer et al., 2001; Kopf, 2002). They are major locations of mud and fluid flow (water, brine, gas, or oil) or erupt from deeper strata to the earth's surface. Submarine MVs are generally confined to shelves, continental and insular slopes and to the abyssal part of inland seas. They are closely linked to high sedimentation rates and tectonic compression, dehydration of clay minerals at depth, or rapid deposition of mass flows. Frequently they form mud domes with diameters of up to a few kilometres and heights of several tens of meters above adjacent seafloor.

MVs are significant sources for the transfer of methane from the geosphere to the hydro- and biosphere. Thus, investigations of $\mathrm{MV}$ and cold seeps are in the focus of ongoing geological, biological, and geochemical studies due to their significance as considerable source locations for the transfer of methane and trace elements to the ocean, as indicators for active transport pathways linking deeper geological strata with the surface, and as environments settled by unique chemosynthetic benthic consortia (e.g. Sibuet and Olu, 1998; Pimenov et al., 1999; Sahling et al., 2002; Levin et al., 2003; De Beer et al., in press). Based on these studies the link between the occurrence of macrobenthos and bacterial mats and geochemical environments, with respect to consumption and release of methane or the sulphur cycle, is well documented. A microbial symbiosis has been detected (Boetius et al., 2000), which is able to consume methane (anaerobic oxidation of methane, AOM). Sulphide, as one of the products of this reaction, is used as energy source by the 
chemosynthetic organisms as giant sulphide-oxidising bacteria like genus Beggiatoa (Boetius et al., 2004; De Beer et al., in press), and symbiotrophic pogonophoran tube worms Sclerolinum sp. and Oligobrachia sp. (e.g. Gebruk et al., 2003; Pimenov et al., 1999; Smirnov, 2000). Due to this "biofilter", related to the microbial consumption of methane, only a certain fraction of the methane is transferred through the sediment-water interface. In order to gain a better understanding of the global methane budget it is of relevance to quantify the amount of $\mathrm{CH}_{4}$ and other greenhouse gas which enters the ocean. The sulphide-oxidising communities Beggiatoa and pogonophorans, in the following also referred as chemoautotrophic communities, indicating methane consumption are thus the objects of interest applying geostatistical techniques.

The HMMV is located at the Norwegian-Barents-Svalbard continental margin $\left(72^{\circ} 00.3^{\prime} \mathrm{N}\right.$ and $\left.14^{\circ} 44.0^{\prime} \mathrm{E}\right)$ (Fig. 2), which is characterised by major submarine slides, large-scale mass wasting, gas hydrates and smaller seafloor features (Vogt et al., 1999). It is situated in a submarine valley on the Bear Island submarine fan, a large complex composed of glacial sediments, covering the entire continental slope and reaches a thickness of more than $3 \mathrm{~km}$ beneath the mud volcano (Hjelstuen et al., 1999). The HMMV is about $1.4 \mathrm{~km}$ in diameter and rises up to $10 \mathrm{~m}$ above the seafloor, to water depths of 1250-1266 m (Jerosch et al., in press). It is a concentric morphologic structure with highly gas-saturated sediments. A flat central zone of grey fluid sediments with a high geothermal gradient (Eldholm et al., 1999) is surrounded by an area with bacterial mats. This central region (crater) is surrounded by elevated sediment features (hummocky periphery) populated by pogonophorans (Pimenov et al., 1999).

\section{Basic principals of interpolation using indicator kriging and estimate quality}

Kriging is a geostatistical method that has been successfully applied to several fields of research. This method, termed by Matheron (1963) and designated after the mining engineer D. G. Krige, was developed and is applied to compute maps from regularly and irregularly distributed data. Since then different types of kriging as ordinary, block or indicator kriging were developed, which allows considering trends or categorical data types ( Isaaks and Srivastava, 1992; Davis, 2002; Olea, 1999).

All kriging types depend on mathematical and statistical models and predict values at non-sampled sites. The addition of a statistical model that includes probability separates kriging methods from deterministic interpolation methods. The Inversed Distance Weight (IDW) method for example uses a simple algorithm based only on the distances between sampling points. Kriging uses a semivariogram model developed by analysing the spatial structure of the data.

Kriging procedures transform data measured or observed at discrete sites to continuous distributions maps. Basically the procedure consists of four steps: 1 . statistical data exploration, 2. variogram analyses, 3. kriging and 4. evaluation of results.

In a first step the dataset is examined with regard to outliers, type of statistical distribution and trends. For identification of outliers, descriptive statistics and statistical tests as well as expert knowledge may be applied. By variogram analyses distance and direction-controlled spatial autocorrelation structures can be examined and modelled. Anisotropies or direction structures may be identified using variogram maps and can be integrated into the interpolation process.

Different variogram models using different settings in terms of the range, the sill and the nugget effect have to be compared to each other by help of cross-validation (see below). The range equals the maximum separation distance within which a distinct increase of semivariogram values can be observed. This is indicative of spatial autocorrelation. The sill corresponds to the semivariance assigned to the range. If anisotropies can be detected, both sill and range can vary with respect to direction. Small-scale variability or measurement errors may lead to high semivariances at nearby locations. The variogram model refers to this in terms of the so-called nugget effect. A pure nugget effect indicates a complete lack of spatial autocorrelation. Further mathematical details are described

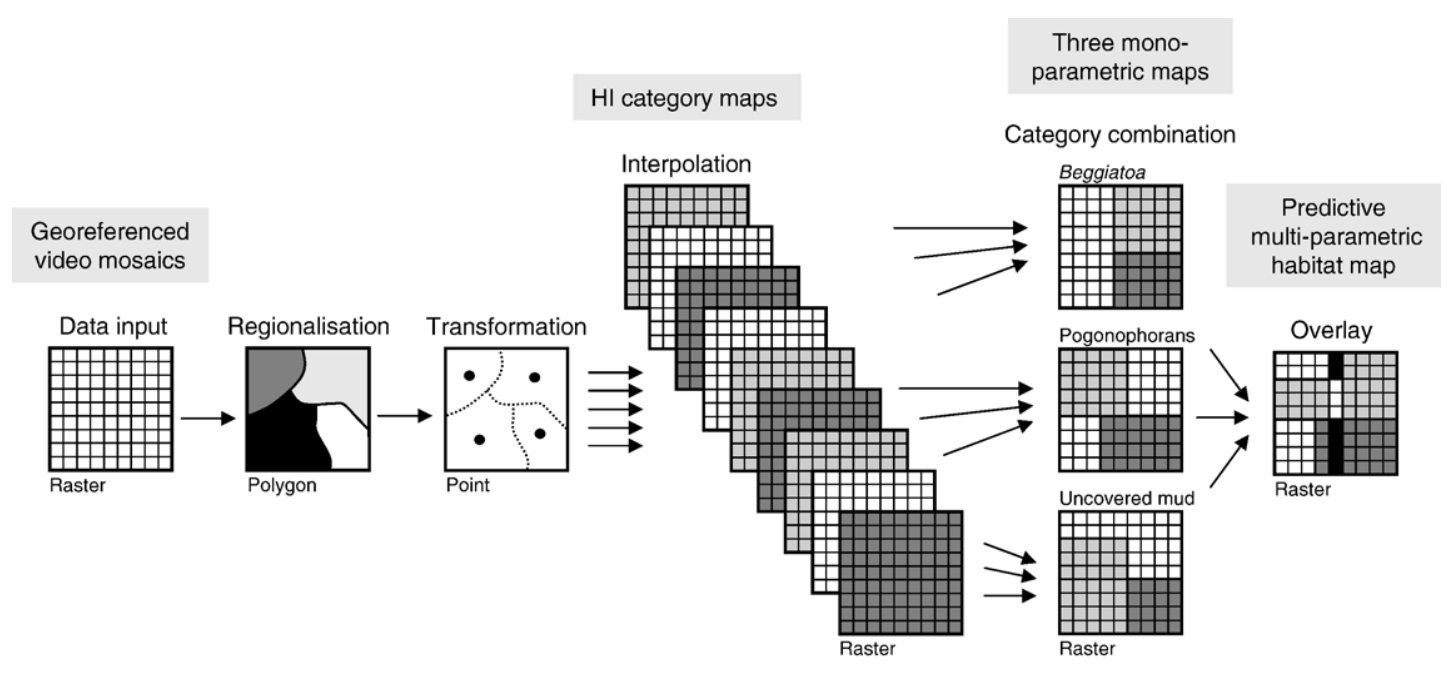

Fig. 3-Schematic description of the GIS based work flow. 
e.g. by Akin and Siemens (1988), Isaaks and Srivastava (1992), Olea (1999) or Webster and Oliver (2001).

In this study cross-validation (a procedure where measured values are removed from the entire dataset and to this reduced dataset variogram analysis and kriging is applied to compute estimates for sites were values were removed) was applied to improve and to control the quality of the applied geostatistical model and thus the results of the spatial analysis. The differences between measured and predicted values, summarised in terms of percentages and statistical mean values, provide a quality control for the model of computation for the habitat map covering the entire HMMV structure.

Characteristic key values were derived from the difference between measured and estimated values obtained by cross- validation: mean error, root mean square of standardised error, and the median of percentage error. The mean error (ME) is computed from the average deviations between measured and estimated values and refers to over- or under-estimations of the variogram models. The ME ideally tends to 0 . The root mean square of standardised error (RMSSE) corresponds to the average relation between the squared deviation of the measured and estimated values at the places $x_{i}$ and the minimum estimation variances (kriging variances) computed there. This value thus reflects the relationship between experimental and theoretical variances. If the RMSSE value is higher than 1, the kriging variances are under-estimated; if it is lower than 1, they are over-estimated. In optimal case the RMSSE value is 1 (Johnston et al., 2001). The RMSSE signifies the level of the relative deviations between measuring and
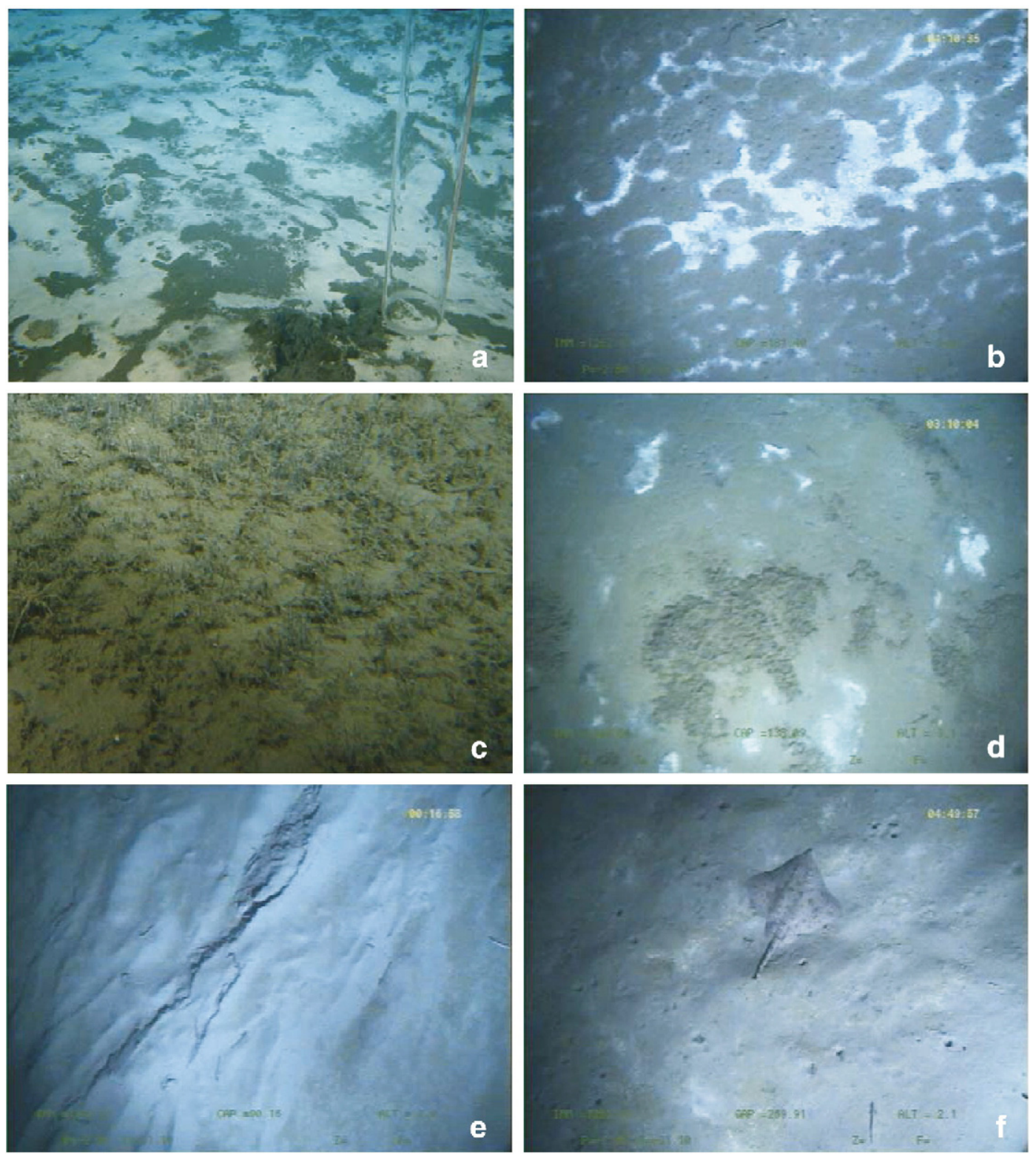

Fig. 4-Exampled for different habitat categories at the HMMV: a. Beggiatoa patches >50\%; b. Beggiatoa patches 20-50\%; c. pogonophorans $>50 \%$; d. Beggiatoa spots 0-20\% and pogonophorans 0-20\%, e. $100 \%$ structured mud, and f. $>50 \%$ smooth mud and 0-20\% Beggiatoa spots (please notice: small holes in the mud, fish, and ray). Still photographs are recorded by Victor6000. 
Table 1 - Categories applied for mapping of biogeochemical habitats of the HMMV

$\begin{array}{lll}\text { Beggiatoa 0-20\% } & \begin{array}{l}\text { Pogonophorans 0- } \\ \text { 20\% }\end{array} & \text { Mud smooth }>50 \% \\ \text { Beggiatoa 20-50\% } & \begin{array}{l}\text { Pogonophorans 20- } \\ \text { 50\% }\end{array} & \begin{array}{l}\text { Mud structured } \\ >50 \%\end{array} \\ \text { Beggiatoa spots 20-50\% } & \begin{array}{l}\text { Pogonophorans } \\ >50 \%\end{array} & \text { Mud smooth 100\% } \\ & & \text { Mud structured } \\ \text { Beggiatoa patches 20- } & 100 \% \\ 50 \% & \\ \text { Beggiatoa spots }>50 \% & & \\ \text { Beggiatoa patches } & & \\ >50 \% & \end{array}$

estimated values. If the respective measured value is defined as $100 \%$, the difference between measured and estimated value can be indicated in percent by the median of percentage error (MPE). A low MPE generally indicates a low deviation between measured and predicted values and therefore a reliable estimation model.

Based on the results of the data exploration and the variogram analyses, the measured data are converted to surface maps. The suitable kriging method depends on the data type, the data distribution, the data properties, and the scientific question. Universal kriging for example is to be applied if comprehensible deterministic trends can be detected.

Indicator kriging (IK) is derived from ordinary kriging and usually used to divide values at locations to two categories by means of a threshold (cutoff) value (or multiple cutoff values): smaller than and larger than the threshold (converting the data from a metric scale into an ordinal scale). But IK is also performed for the spatial generalisation of geological or biological information, when categorical data as the occurrence/absence of benthic epifauna (e.g. Rivoirard et al., 2000) is studied.

In this study several coverage degrees of occurrences or absence of chemoautotrophic communities (categories) are extracted from video material as polygons, which are used at the outset. Each of the polygons is at a time selected for binary inspection relating to the categories. In case of the occurrence of the certain species or sediment type the value 1 , and in case of its absence the value 0 is assigned to the measuring location. Categorical data are thus converted into binary data before the interpolation of the centroids of the polygons. With IK spatial probability maps (one for each category) are computed for the occurrence of the respective species or sediment type. The interpolation results can also be interpreted as the percentage probabilities; for example: "with a probability of $85 \%$ muddy sediment will occur".

The combination of the category maps within the GIS allows the comprehensive view on graduated occurrence of e.g. bacteria not only onto one category provided typically by IK maps.

\section{Material and methodical realisation}

\subsection{Data acquisition: georeferenced video mosaicing}

During the RV Polarstern expedition ArcXIX3b (Klages et al., 2004) a video system was attached at the bottom of the ROV Victor6000
(Ifremer) (Fig. 1). During the dives the position of the ROV was determined by highly accurate Ultra Short Base Line (USBL) navigation system (Jouffroy and Opderbecke, 2004). The ROV was operated at a maximum altitude of $3 \mathrm{~m}$ above seafloor (in a water depth of $1255 \mathrm{~m}$ to $1265 \mathrm{~m}$ ) with a speed of $0.3 \mathrm{~m} \mathrm{~s}^{-1}$. The video system had an optical aperture of $60^{\circ}$. At an altitude of $3 \mathrm{~m}$ above seafloor the video observations by the ROV has a width of $3 \mathrm{~m}$, therefore. This ensured a high image quality and allowed realtime video mosaicing of the seafloor by the software MATISSE (Mosaicing Advanced Technologies Integrated in a Single Software Environment), which was developed by the French Research Institute for Exploitation of the Sea (Ifremer). During the mosaicing process, one mosaic arises each half a minute merging about 500 images recorded by the video camera. Each mosaic covers an area of about $3 \mathrm{~m}$ of width and $6-7 \mathrm{~m}$ of length (pixel width $8.3 \mathrm{~mm}$ ).

In total about $24 \mathrm{~km}$ of video mosaicing were recorded during six ROV dives (35 hours dive time). MATISSE (Allais et al., 2004; Vincent et al., 2003) produces online digital merging georeferenced mosaics (geotiffs) using the video input and the high precision underwater navigation. A small displacement between two consecutive images is required by the video mosaicing algorithms based either on feature tracking (Shi and Tomasi, 1994) or robust optic flow methods (Odobez and Bouthémy, 1994). The georeferenced mosaics are visualised and analysed within a Geographical Information System (GIS).

A total amount of 2840 mosaics was visually inspected; the different biogeochemical habitats were identified and mapped as polygons on the video mosaics with the GIS. Variogram analysis and kriging was applied to a so-called working dataset consisting of 2310 images. The remaining 530 mosaics were used for validation purpose which allows comparing the estimates derived by the geostatistical analysis with an additional independent dataset.

\subsection{Data analysis}

The work flow for the development of three mono-parametric maps (MPM) from image data which form the basis for a detailed habitat map of the HMMV is represented in Fig. 3. As a first step the raster data consisting of 2840 georeferenced video mosaics are imported into the GIS and areas of Beggiatoa, pogonophorans and uncovered mud are digitised as polygons (regionalisation).

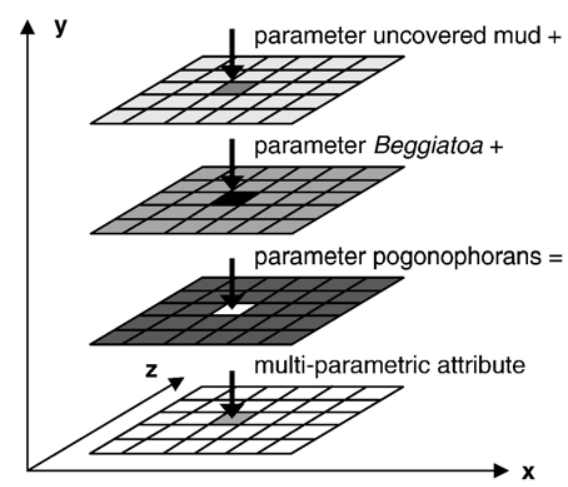

Fig. 5-GIS-based overlay technique producing multiparametric surfaces. 


\section{GIS data transformation}

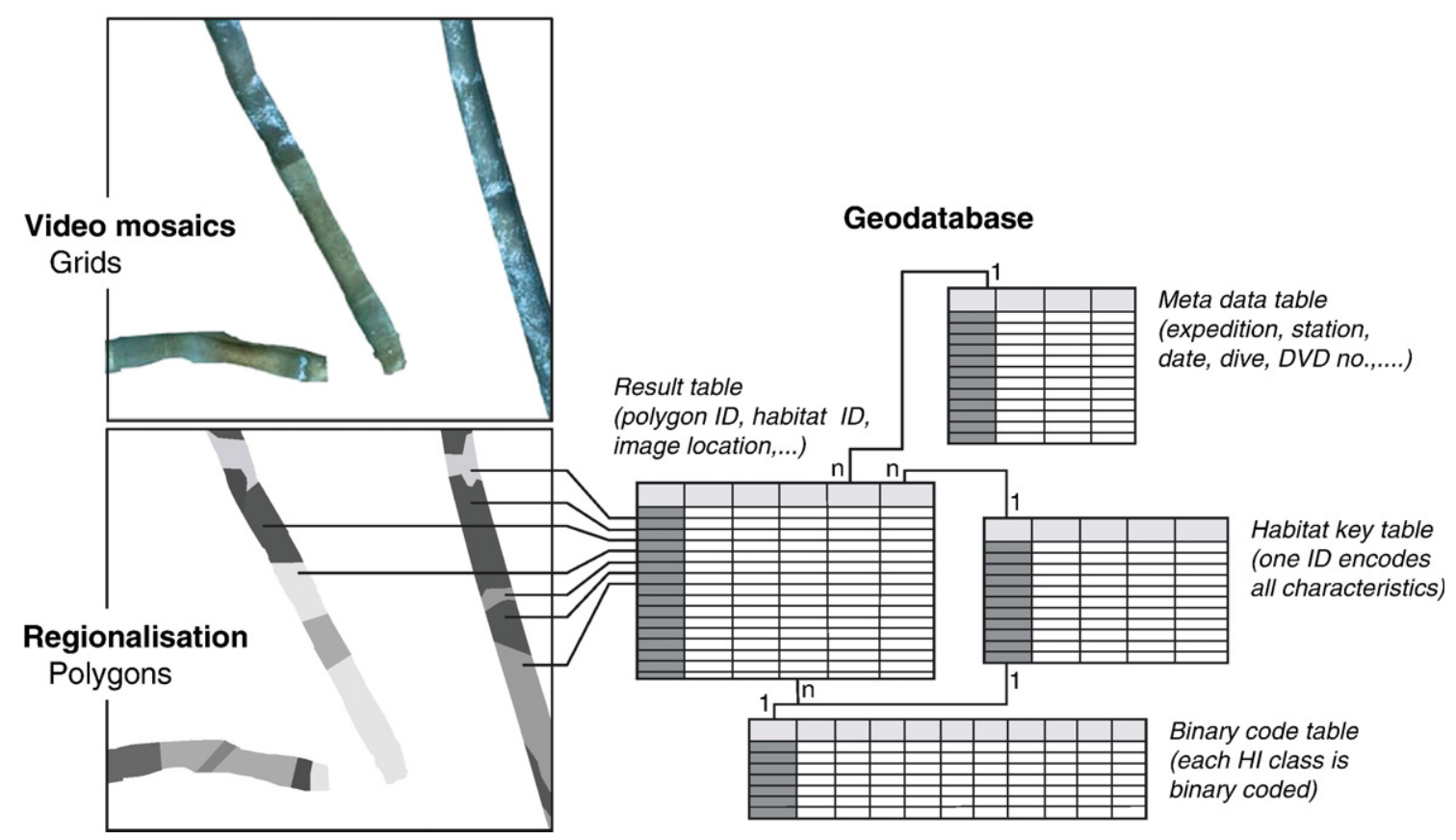

Fig. 6-GIS-based data simplification and data management.

To each polygon the attribute (category) according to the classification scheme (see below) was assigned. For a transformation of polygons to point data the centroids coordinates of the polygons and the assigned attributes are used for the interpolation by means of indicator kriging. By these means one raster map was generated for each classification category (cell size $3 \times 3 \mathrm{~m}$ ). Finally, a mono-parametric map is created with the help of GIS techniques, by a combination of all category maps of one parameter (e.g. Beggiatoa). A further overlay of the monoparametric maps (Beggiatoa, pogonophorans and uncovered mud) can result in a detailed predictive multi-parametric habitat map for the HMMV. The MPMs are used for an overlay to a multiparametric habitat map, and area computations are conducted with respect to the source location of mud flows and pattern of biogeochemical habitats allowing conclusions on the biogeochemistry of the HMMV (Jerosch et al., in press).

\subsection{Habitat indicator coding and GIS implementation}

By the video surveys a significant part of HMMV was covered which allowed to identify and map sedimentological and biological features at the seafloor and the distribution of different biogeochemical habitats as Beggiatoa, pogonophorans or mud flows.

Basically, the HMMV can be grouped into three major spatial entities according to the habitat indicators: (i) uncovered mud of either a very young mud flow, not yet inhabited by Beggiatoa, or old mud flow; (ii) occurrences of Beggiatoa which indicates intense methane consumption (anaerobe oxidation of methane - AOM) taking place beneath the seafloor; (iii) pogonophorans indicating a lower $\mathrm{CH}_{4}$ consumption and older mud flow. For the uncovered mud highest methane release into the bottom water is expected due to the missing "biofilter" by indicating Beggiatoa or pogonophoran population.
These three parameters determine the biogeochemical habitats at the HMMV. In addition Beggiatoa and pogonophorans occur together and form transition zones covered by e.g. Beggiatoa (coverage of 0-20\%) and pogonophorans (coverage of $>50 \%$ ). The attribution for example assigning only the category pogonophorans $20-50 \%$ to an area, signifies automatically a $50-80 \%$ uncovered mud fraction. Non-colonised mud, Beggiatoa, and pogonophorans (examples are shown in Fig. 4) were classified based on their degree of coverage (Table 1).

About $24 \mathrm{~km}$ (17 km working dataset and $7 \mathrm{~km}$ validation dataset) on 2840 georeferenced video mosaics were analysed by visual inspection loaded at a time into a GIS (ArcGIS 9.1, ESRI). The digitisation of the mosaic contents produces an enormous data reduction from raster data to vector data which is required for a further analysis.

The resulting 1578 polygons were featured with the contents of the mosaics concerning the classification scheme in Table 1. All categories given there are coded binary related to their occurrence in the dataset and surface maps are calculated using the centroids of the polygons by means of IK for all 13 categories. The combination of the category maps of one parameter (e.g. Beggiatoa) yields into a mono-parametric map. The MPMs in general are the basis for multi-parametric overlay maps. Two or more spatially overlapping input data layers of geometrical type polygon, line or point will be overlaid geometrically producing a new multi-parametric data layer (Fig. 5). A GIS-based overlay of all MPMs would reveal e.g. in a transition zone of Beggiatoa and pogonophorans and thus in a complex view of the habitat distribution of the HMMV.

The analysis of the images was done by measuring the extent of specific items as spots $(<30 \mathrm{~cm})$ and patches $(>30 \mathrm{~cm})$ of bacteria, pogonophorans or mud within the GIS. Areas are 

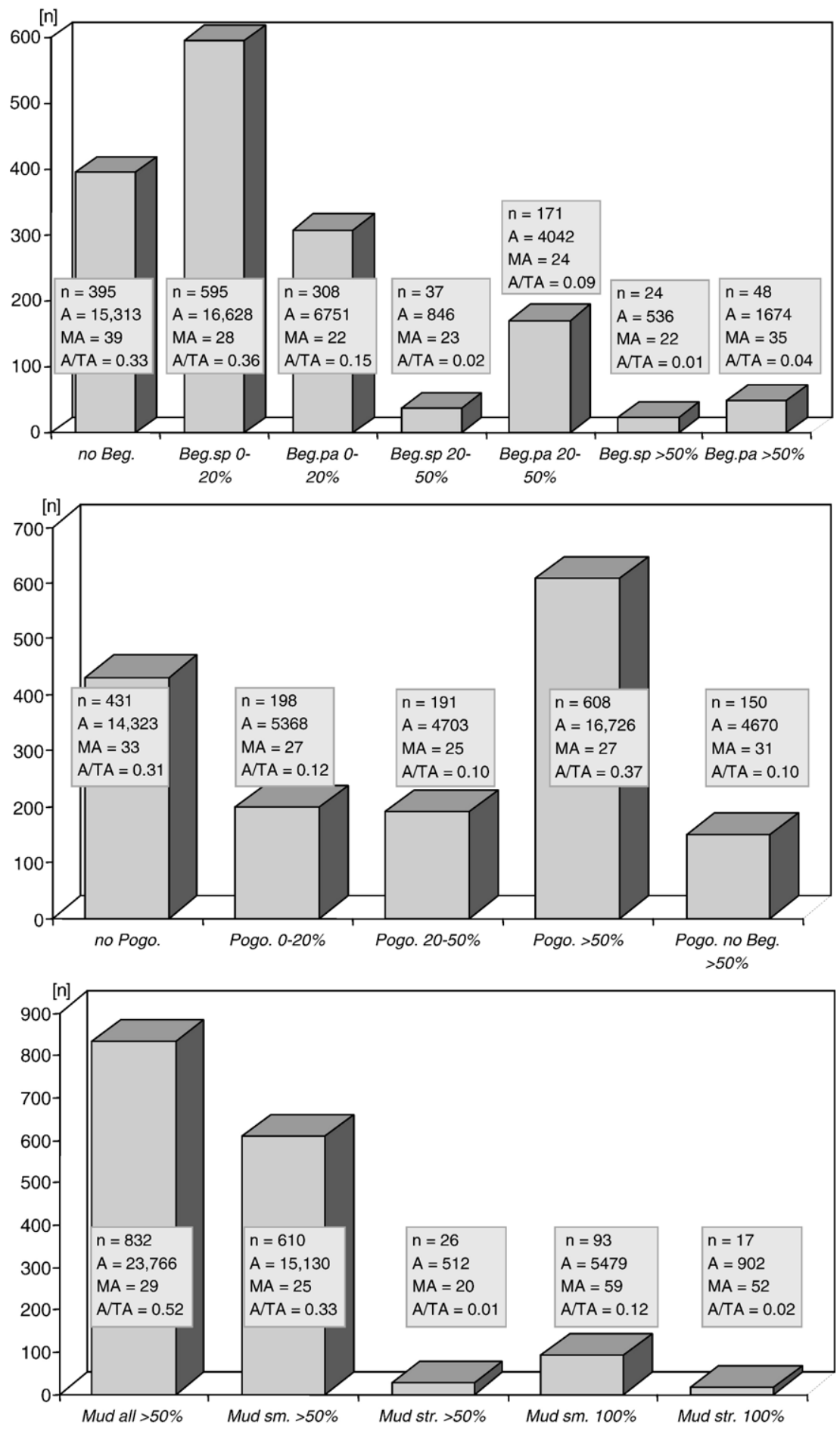

Fig. 7-Data distribution of the parameters Beggiatoa, pogonophorans and uncovered mud corresponding to polygons of the working datasets (Fig. 8d). The number of polygons $(n)$, the area $(A)$ which is covered by the parameter, the averaged area of one polygon (MA), and the ratio areas of coverage to the total area of investigation ( $A / \mathrm{TA})$ with regard to the parameter. Areas are given in $\mathbf{m}^{2}$.

digitised as polygons (Fig. 6) with respect to the defined categories, and are provided with keywords concerning their habitat indicating characteristics and metadata. For the indicator kriging procedure each category is to be coded binary regarding to its occurrence (yes=1 or no=0). All the information was stored within a relational geodatabase system (Fig. 6).

\section{Results}

The results of this study are presented in two steps: first the presentation of the resulting working dataset, the generated MPMs including variogram analysis and the visual control of 


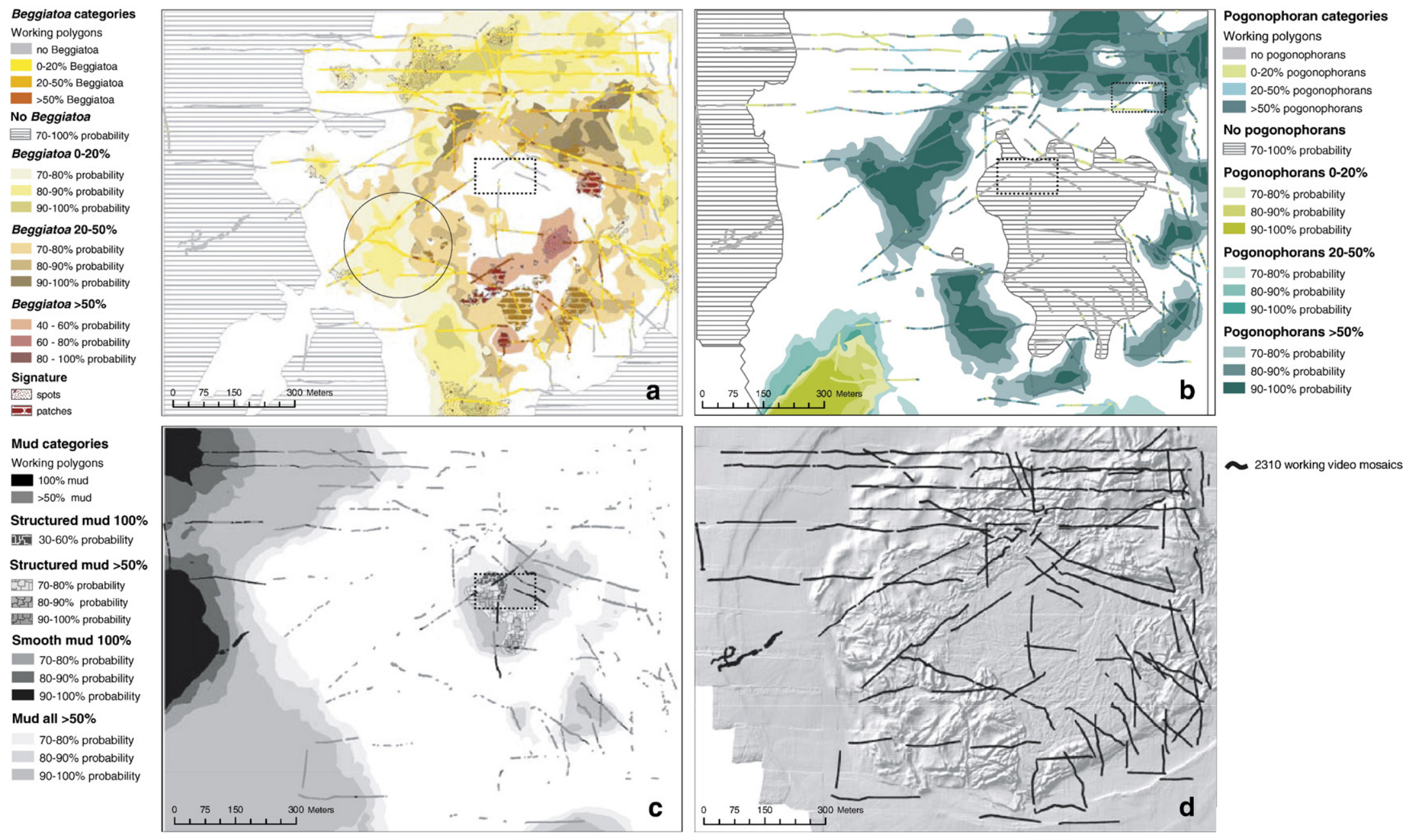

Fig. 8-(a-d) Distribution of analysed polygons and predictive surfaces after indicator kriging: (a) Beggiatoa, (b) pogonophorans, and (c) uncovered mud. Colours are arranged gradually concerning their probability of occurrence (Table 2). Polygons appear as lines with respect to the scale of the map. If no significant differences can be recognised between the appearing lines and the interpolated surfaces, the variogram model fits well. Blank areas indicate a probability of occurrence less than the lowest probability value given in the legend. (d) Data distribution of the entire working dataset. The encircled area provides an example for a reliable fit, whereas within the rectangles the correspondence between observed and predicted categories is weaker (for details see text). 
Table 2 - Absolute and relative values of the interpolated surfaces at the HMMV

\begin{tabular}{|c|c|c|c|c|c|c|}
\hline & \multirow[t]{3}{*}{ HI coverage degree } & \multirow{3}{*}{$\begin{array}{l}\text { Interpolated } \\
\text { areas }\left[\mathrm{m}^{2}\right]\end{array}$} & \multirow{3}{*}{$\begin{array}{l}\text { Percent } \\
\text { of } \\
\text { coverage }\end{array}$} & \multicolumn{3}{|c|}{ Probability of occurrence in $\%$} \\
\hline & & & & \multicolumn{2}{|c|}{ User defined } & \multirow{2}{*}{$\begin{array}{c}\text { GIS calculated } \\
\text { Mean }\end{array}$} \\
\hline & & & & Min & Max & \\
\hline \multirow[t]{4}{*}{ Pogon. } & Pogonophorans no & 297,746 & 24.49 & 70 & 100 & 92 \\
\hline & Pogonophorans 0-20\% & 36,649 & 3.01 & 70 & 100 & 90 \\
\hline & Pogonophorans $20-50 \%$ & 43,295 & 3.56 & 70 & 100 & 84 \\
\hline & Pogonophorans $>50 \%$ & 276,121 & 22.71 & 70 & 100 & 93 \\
\hline \multirow[t]{9}{*}{ Beggiatoa } & Beggiatoa not predicted & 304,424 & 26.68 & & & \\
\hline & Beggiatoa no & 318,745 & 27.93 & 70 & 100 & 87 \\
\hline & Beggiatoa $0-20 \%$ & 250,200 & 21.92 & 70 & 100 & 80 \\
\hline & Beggiatoa $20-50 \%$ & 163,077 & 14.29 & 70 & 100 & 83 \\
\hline & Beggiatoa spots $20-50 \%$ & 43,815 & 3.84 & 70 & 96 & 76 \\
\hline & Beggiatoa patches $20-50 \%$ & 22,699 & 1.99 & 70 & 100 & 76 \\
\hline & Beggiatoa $>50 \%$ & 29,078 & 2.55 & 40 & 86 & 69 \\
\hline & Beggiatoa spots $>50 \%$ & 2357 & 0.21 & 40 & 50 & 41 \\
\hline & Beggiatoa patches $>50 \%$ & 6809 & 0.60 & 40 & 100 & 44 \\
\hline \multirow[t]{5}{*}{ Mud } & Mud all $>50 \%$ & 689,563 & 58.39 & 70 & 100 & 96 \\
\hline & Mud smooth $>50 \%$ & 276,917 & 17.02 & 70 & 100 & 85 \\
\hline & Mud structured $>50 \%$ & 12,256 & 23.45 & 70 & 100 & 92 \\
\hline & Mud smooth $100 \%$ & 200,974 & 0.10 & 40 & 45 & 41 \\
\hline & Mud structured $100 \%$ & 1182 & 1.04 & 70 & 99 & 76 \\
\hline
\end{tabular}

the interpolated surfaces using the working datasets. The second step consists of a validation of the quality of the MPMs which is performed by cross-validation of the indicator kriging models and visual inspection using a validation dataset of further analysed video mosaics.

\subsection{Predictive mono-parametric habitat maps at the HMMV}

The working dataset is made up by 2310 of the 2840 visually inspected video mosaics. They are analysed with regard to the coverage degree of the parameters Beggiatoa, pogonophorans and uncovered mud. The resulting dataset consisting of 1578 polygons is used for the compilation of the three monoparametric maps within GIS. The working dataset corresponds to a total area of investigation (TA) of $45,790 \mathrm{~m}^{2}$ (15.3 km ROV transect $\times 3 \mathrm{~m}$ image width). The distribution of the data assigned to the respective parameter categories is given in Fig. 7. For example, the category Beggiatoa spots $0-20 \%$ is represented most frequently (number of polygons ( $n$ ) is 595) covering an area of $6751 \mathrm{~m}^{2}(\mathrm{~A})$. The average area (MA) of one polygon of this category covers an average area of $28 \mathrm{~m}^{2}$ (Beggiatoa spots, defined as $<30 \mathrm{~cm}$, are clustered into areas). Furthermore, this category is assigned to $36 \%(\mathrm{~A} / \mathrm{TA}=0.36)$ of the total area of investigation. Including the categories "no Beggiatoa" (33\%) and Beggiatoa patches $0-20 \%(15 \%)$ these three categories represent the majority (84\%) of the analysed surface. The spatial distribution of the working dataset is shown in Fig. 8. The polygons, representing the video mosaicing tracks as shown in Fig. 6, there appear as lines with respect to the scale of the map.

According to Journel and Huijbregts (1978) the variogram calculations were performed exclusively for distances below half of the maximum horizontal extension of the area under investigation (here $\sim 0.7 \mathrm{~km}$ ). Cross-validation was used as the method to select the optimum variogram model: it was intended to minimise MPE and concomitantly approximate ME toward 0 and RMSSE toward 1. For the surface calculations the mean distance of each observation site to its nearest neighbour was used as the cell (lag) size. The number of lags allocated to each lag size was adjusted to ensure that significant autocorrelation (range) became clearly visible in the variogram window. If the semivariances displayed on the variogram map indicated anisotropies in the data field, different ranges for different directions (to account for anisotropies) were compared with each other.

For the kriging calculations the raster was set according to the average mean distance of each measurement site in relation to its nearest neighbour. The searching or variogram window within measured values were included to estimate a certain

Table 3-Quality of estimation by means of statistical average values resulting from cross-validation

\begin{tabular}{lrrr} 
Parameter & ME* $^{*} 0^{-3}$ & RMSSE & MPE \\
\hline Beggiatoa no & -1.588 & 1.009 & 16.12 \\
Beggiatoa 0-20\% & -0.354 & 1.004 & 36.52 \\
Beggiatoa $20-50 \%$ & 0.184 & 0.998 & 8.02 \\
Beggiatoa spots $>50 \%$ & 0.080 & 1.090 & 2.11 \\
Beggiatoa patches $>50 \%$ & -0.014 & 1.047 & 0.00 \\
Pogonophorans no & 0.145 & 0.990 & 4.85 \\
Pogonophorans 0-20\% & -2.880 & 1.001 & 9.56 \\
Pogonophorans 20-50\% & -5.836 & 0.997 & 30.34 \\
Pogonophorans $>50 \%$ & 0.618 & 1.008 & 30.17 \\
Mud all $>50 \%$ & -1.681 & 1.038 & 31.16 \\
Mud smooth $>50 \%$ & -2.044 & 1.002 & 35.85 \\
Mud structured $>50 \%$ & -0.572 & 0.986 & 0.00 \\
Mud smooth 100\% & 0.029 & 0.989 & 0.00 \\
Mud structured 100\% & 0.074 & 0.973 & 0.00 \\
\hline
\end{tabular}



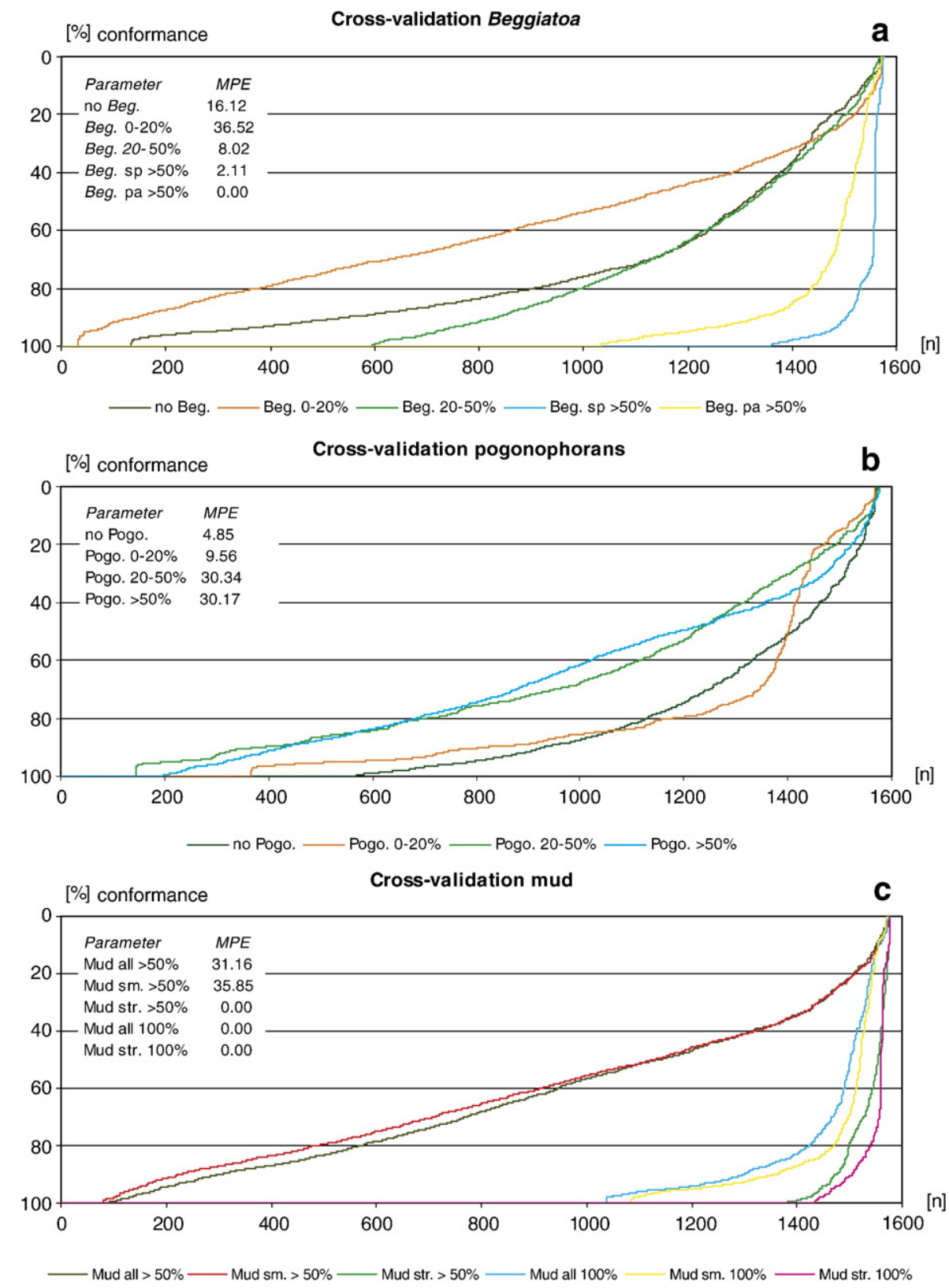

Fig. 9-(a-c) Results computed by cross-validation: visualisation of percentage errors and median percentage errors (MPE). The abscissa gives number of polygons and the ordinate the conformance between measured and predicted values after a full crossvalidation of 1578 polygons (note the scale of the ordinate is inverted).

point was adjusted to the range of the variogram model. A foursector neighbourhood was defined to avoid directional bias.

After the IK interpolation the combination of the category maps results in three MPMs (Fig. 3). The MPMs contain the predictive surfaces at the HMMV that are covered by the parameter, respectively (Fig. 8a-c). Each MPM is colour coded distinctively according to the different categories (e.g. yellow: Beggiatoa 0-20\% coverage, orange: Beggiatoa $20-50 \%$ coverage and red: Beggiatoa $50 \%$ coverage). The degrees of occurrence probability is then gradually arranged (light yellow corresponds to a smaller probability than dark yellow, etc.). Blank areas do not imply no occurrence of the parameter, but a probability occurrence less than e.g. $70 \%$, respectively to the minimum thresholds given in Table 2. No occurrence areas are indicated apart.

Visual control of the interpolated surfaces can be performed by overlaying the polygons of the working dataset with the raster maps. For this purpose, the working dataset is coloured equally to the parameter categories (Fig. 8a-C). If no significant differences can be recognised between the appearing lines and the interpolated surfaces, the variogram model is well fitted to the data (encircled area in Fig. 8a). At other sites - apparently at all MPMs - a visual impression of underestimate arises, and it seems that blank regions should have been assigned to a parameter category. This impression results from the ambitious defined minimum 


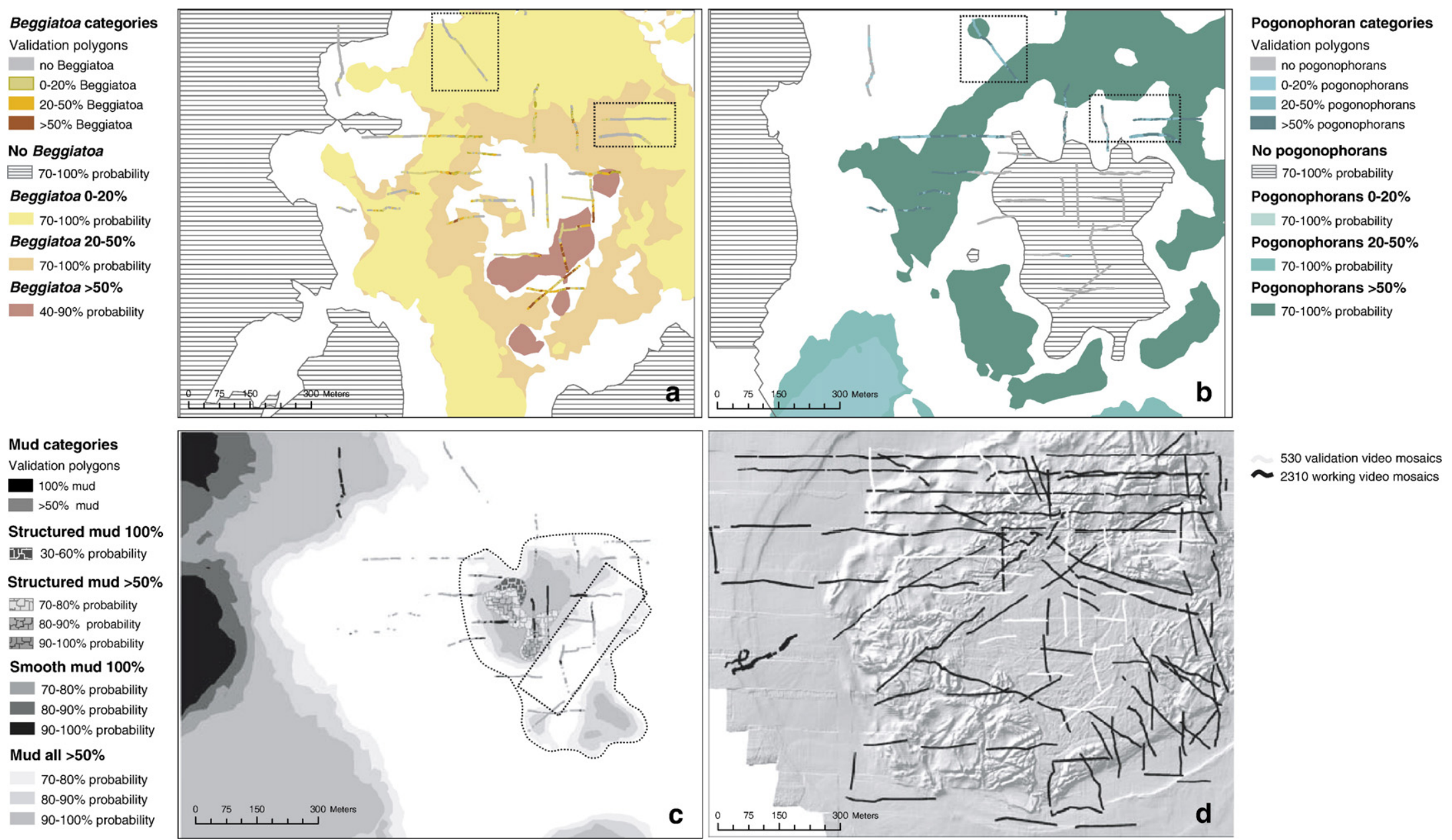

Fig. 10-(a-d) Validation dataset combined with simplified mono-parametric maps. (a) Beggiatoa, (b) pogonophorans and (c) uncovered mud. (d) distribution of the entire validation dataset. Significant deviations of the validation polygons to the MPMs are highlighted by rectangles. 
threshold of occurrence probability (Table 2). Blank area are thus not assigned to no category but to a probability of occurrence less than a 70\%, for example, for the mud classes (note legends in Fig. 8).

The IK interpolation produces probability values for the occurrence of a feature between 0 and 1 . They were transformed into percentages (Table 2). Both surfaces with high probability of occurrence as well as surfaces with high probability of exclusion of the parameter category can be assigned. Minimum and maximum threshold values are defined manually oriented on the calculated mean probability values. The average value gives the overview of the general estimation quality; the minimum and maximum threshold values are important because they correspond directly with the areas and their graduated colours in the MPM (Fig. 8a-c). Table 2 contains the three values associated to each parameter category and gives, therefore, information about the interpolated surfaces.

In general reasonable results in nearly all analysed parameter categories were achieved, except in the categories of, "Beggiatoa $>50 \%$ " and "smooth mud 100\%". Here the results contain a certain degree of uncertainty.

\subsection{Validation of the results applying cross-validation and a validation dataset}

When performing validation, two datasets are used: a working and a validation dataset. The working dataset contains the measured locations on which the variogram analysis applied for prediction is based. Calculated statistics, resulting from leave-one-out cross-validation, serve as diagnostics that indicate whether the model and its associated parameter value are reasonable.

The validation dataset is used to prove the interpolated predictions independently from the variogram analysis by the results of the visual inspection of further 530 video mosaics.

\subsubsection{Evaluation of the prediction models (variograms) derived from cross-validation}

The so-called leave-one-out cross-validation involves subtracting a single observation from the working dataset and calculating this single observation from the remaining observations. This is repeated such that each observation in the working dataset is used once as the single observation. Such a cross-validation was applied for each of the 13 binary coded categories (Table 1) predicting each of the polygons of the working dataset by using the specific variograms. This allows comparison of results derived by the reduced dataset with the results derived by the complete working dataset. From the cross-validation errors the percentage conformance (and/or deviation) were expressed as single values for each parameter category; their median value is defined as the median percentage error (MPE). Furthermore, three averaged key parameters are calculated from the distribution to characterise the quality of the chosen variogram models (Table 3).

The graphs in Fig. 9a-c show the percentage error of the single values for selected categories grouped by parameter. These single values result from a full cross-validation, predicting each of the 1578 polygons (X-axis) by the help of the reduced dataset and the percentage differences between measured and predicted values. The percentage of conformance is given then on the $y$-axis. For instance, 1361 of the 1578 polygons of the category Beggiatoa spots $>50 \%$ (blue line) are forecast accurately (100\%). The graph intersects the ordinate at an $x$-value of 1545 polygons, signifying a conformance of these polygons of $80 \%$ with the variogram model.

Considering graphs in Fig. 9a-c the variograms fit particularly well with the categories Beggiatoa $>50 \%$ and mud $100 \%$ coverage. In these categories the majority of the polygons (more than 1000 of 1578) coincide to $100 \%$ comparing examined and predicted values: 1361 polygons of the category Beggiatoa spots $>50 \%$ are predicted precisely, as well as 1033 polygons of Beggiatoa patches $>50 \%, 1030$ polygons of mud all $100 \%, 1085$ polygons of smooth mud $100 \%$, and 1435 polygons of structured mud 100\%. For the category Beggiatoa spots $>50 \%$ further 71 polygons are predicted with up to $90 \%$ conformance, i.e. 1432 of 1578 polygons (90.8\%) are well determined (Fig. 9a). Furthermore, the quality of the tube worm estimation model appears visibly in a reliable way for the categories "no occurrence of pogonophorans" and "pogonophoran coverage 0-20\%", while the other two categories (20-50\% and 50\%) are represented rather moderately (Fig. 9b).

The performed averaged key values are summarised in Table 3, which demonstrates among others the ME, RMSSE and the MPE values. Both the ME and the RMSSE indicate neither crucial under- nor over-estimation and, therefore, no bias in the surface estimations: ME shows that the average cross-validation errors equal almost zero and RMSSE equals almost 1 in all cases. The MPE can be observed to be low for the categories: mud structured $>50 \%$; mud smooth $100 \%$; mud structured 100\%; Beggiatoa 20-50\%; Beggiatoa spots $>50 \%$, and Beggiatoa patches $>50 \%$. Highest MPE are found for Beggiatoa 0-20\% and mud smooth $>50 \%$.

\subsubsection{Estimation of the predictive mono-parametric maps using a validation dataset}

Subsequent to the statistic estimate of the quality of the respective IK model, the final control of the resulting IK surfaces follows with help of a validating dataset. This dataset was not used for the determination of the geostatistical data structure and thus gives pure information whether the interpolated surfaces approximate to further analysed data.

The validating dataset consists of an examined surface of $9358 \mathrm{~m}^{2}$, which is transformed into 675 polygons, resulting from the visual analysis of 530 video mosaics. Therefore, a fifth of the 2840 examined mosaics were used as controlling dataset. In Fig. $10 \mathrm{a}-\mathrm{c}$ the results of this investigation are intersected with the kriged surfaces of the MPM enabling a direct comparison. Fig. 10d shows the spatial distribution of the working dataset in black and the validation dataset in white colours.

Deviations become visible for all three parameters, but the agreements outweigh and confirm the general spatial structure of the data, and/or the spatial distribution of the probability of occurrence. In case of Beggiatoa it is noticeable that particularly in the north and north-east of the HMMV centre (see rectangles in Fig. 10a) the interpolated surfaces represent rather an over-estimation of the bacteria occurrence. In these areas it becomes clear - on the basis of the validating data record - that pogonophorans are certainly outbalanced there (rectangles Fig. 10b). However, the 
exclusion surfaces of these two parameters are predicted particularly well. The validation polygons of the parameter mud (Fig. 10c) particularly underline occurrences of uncovered surfaces in the centre of the HMMV. Here, the polygons clarify that an underestimation of this parameter is probably the case. Note that at the blank areas the mud categories are not excluded, but attributed to a probability of occurrence of less than $70 \%$.

\section{Discussion}

The representation and area calculation of irregularly distributed data is in the focus of all territorial geochemical balancing methods or definition of protection zones. The surface exactness of specific oceanic regions, as the estimate of global marine primary production (Longhurst, 1998), benthic material flux (Zabel et al., 2000), or the distribution of chemoautotrophic organism is always related to surface areas. Therefore, the interpolation of points into surfaces represents an important gain of information. Resulting monoparametric maps are the basis for complex multi-parametric maps. For this purpose the quality assessment of the MPMs is an important factor. Within this study statistical (IK and crossvalidation) and visual (working and validation polygons) methods were used to generate surface maps describing the spatial distribution of three parameters occurring at the HMMV. These methods enable to evaluate the quality of the mono-parametric maps with regard to the Tables 2 and 3 as well as in the Figs. 8-10.

The average probability values in Table 2 , calculated within the GIS, describe very credible values for all Beggiatoa categories except for "spots and patches $>50 \%$ ". Fig. 8 correlates directly with Table 2, i.e. all represented Beggiatoa surfaces (Fig. 8a) except "spots and patches $>50 \%$ " are predicted with high values and thus with high probability of occurrence. "Spots and patches 50\%" surfaces represented in Fig. $8 \mathrm{a}$ are predicted with less probability than the remaining Beggiatoa categories. Even these surfaces are provided with reliable MPE values indicating high conformance between measured and predicted values (Table 3 and Fig. 9a) and a high quality of the applied IK models. This combination suggests that the prediction of these surfaces is limited regionally; assigning a colonisation density closely related to certain geochemical conditions. This assumption is confirmed by the regional distribution of the Beggiatoa categories $>50 \%$ also within the validation dataset illustrated in Fig. 10a.

On the basis of the graphs in Fig. 9a the quality of the estimation model appears for each category. It can be determined which of the IK models worked in a confidential way by the percentage errors derived from cross-validation. Such a representation of the single percentage errors helps to make the interpolated maps more transparent. All Beggiatoa categories achieve satisfying MPE values, only the MPE for the category $20-50 \%$ coverage turned out comparatively high (Table 3). This class is the most frequently occurring class within the working dataset (Fig. 7), which is spatially distributed on a large area. This could explain the high probability average value of occurrence (Table 2) for the areas in Fig. 8a, but also the fuzziness of the IK of model for that category.
The distribution of the forecast surfaces which are not covered by the bacteria is limited to the region outside of the HMMV. This could be confirmed neither by visual video mosaic analysis (concerned surface are highlighted by a rectangle in Fig. 8a) nor during the ROV dive experiences of scientists. It is known that in the centre of the HMMV a surface exists completely uncovered by Beggiatoa or pogonophorans. On the result map Beggiatoa are not excluded which would be then assigned by shaded surfaces (rectangle Fig. 8a). Nevertheless, areas are blank resulting from the adjusted minimum threshold in Table 2. Regarding to this region concerning the two other parameters, pogonophorans are also excluded there (rectangle Fig. 8b), but for mud a probability of over $70 \%$ is calculated (rectangle Fig. 8c). Concluding reversely, the probability of occurrence for Beggiatoa is only $30 \%$ maximum.

The category Beggiatoa $20-50 \%$ attains both a good estimate for the interpolated probability of occurrence values and for the cross-validation average values. Furthermore, this category achieves applicable results also after the control using the validation polygons.

For all pogonophoran surfaces in Fig. 8b reliable probability of occurrence average values could be determined with the help of cross-validation procedures (Table 2). However, the IK model is of a better quality in the categories no pogonophorans and $0-20 \%$ coverage than for the other two classes (20-50\% and $>50 \%$ ). Thus, the surfaces of the two latter categories are predicted more uncertainly than those of the first mentioned. Regarding the pogonophoran distribution within the working dataset, a conspicuous region is observed in the northwest of the HMMV where a too small spreading of the interpolated surface is probable. This impression is affirmed by the validating dataset (rectangles Figs. $8 \mathrm{~b}$ and $10 \mathrm{~b}$ ).

The validating dataset shows that the data distribution of the working dataset used for IK led to further insufficient estimates in the interpolated surfaces northeast of the mud volcano centre (rectangles Figs. $8 \mathrm{~b}$ and $10 \mathrm{~b}$ ). There, it becomes apparent that the pogonophoran surfaces $>50 \%$ should probably have been predicted more extensively to the centre of the mud volcano, while the Beggiatoa $20-50 \%$ surfaces were probably computed too expanded.

Evaluating all applied control mechanisms (visually predicted on the basis the Figs. $8 \mathrm{~b}$ and $10 \mathrm{~b}$ and statistically on the basis the Tables 2 and 3), the kriged surfaces which are not colonised by pogonophorans are predicted reliably: both outside of the HMMV (reasonable by missing geochemical characteristics of the sediment pore water) and in the central mud volcano area (justified by high temperatures, fresh mud flows and a temporal hierarchy in the colonisation structure of the chemoautotrophic organisms Beggiatoa and pogonophorans) (Jerosch et al., in press).

A special ecological meaning is attached to the uncovered and almost uncovered surfaces in the active centre of the mud volcano, because the highest methane release into the hydrosphere is expected due to the absence of biofilter indicating chemoautotrophic communities (Boetius et al., 2000; Damm and Budéus, 2003; De Beer et al., in press). The data distribution of the completely uncovered mud surfaces (mud 100\%), in addition, the category mud all $50 \%$ is well converted into the IK models (Table 2), while the low probability of occurrence does not permit a supra-regional 
interpretation of surfaces in the MPM (similar to the Beggiatoa categories $>50 \%$ ). Also the graphs of the percentage errors of these five classes are quite similar (Fig. 9a and c). The mud categories show that the MPE is not always meaningful enough, as to be seen by the example of the comparison of the categories " $50 \%$ structured, $100 \%$ smooth, and $100 \%$ structured". All three MPEs are 0 (Table 2); only the individual percentage error values classify a qualitative order, which is also reflected in the ME values. Hence, the IK model of the category smooth mud $100 \%$ is adapted best to the data distribution.

The data density (high and sporadically arising) has different weight of impact due to the IK function in the area (e.g. Richmond, 2005; Webster and Oliver, 2001). According to visual impressions of the validating evaluation, the mud surfaces seem to be slightly underestimated in the centre of the HMMV (see rectangle in Fig. 10c). Conducting an interpolation with both datasets would probably be more expanded and the individual central mud surfaces would be then connected to one large area as, for instance the polygon drawn manually in Fig. 10c.

\section{Conclusions}

Based on a rather dense dataset information about nonsampled seafloor areas is predicted with the help of the geostatistical method indicator kriging. This could be conducted successfully due to a large amount of exclusive video mosaics taken up with the ROV Victor6000, which were provided furthermore with geographical coordinates. Data acquisition with a ROV is a time- and cost-intensive work. The approach was to extract categorical information from image data, to transform them into binary coded (0/1) discrete variables and to extrapolate them GIS-based into monoparametric surface maps.

Interpolation procedure represents a gain in information over unsampled areas, however, with the restriction that the results always remain a degree of uncertainty; therefore interpolation cannot replace real measured values and the result of an interpolation becomes ever better, the more largely the used data density. However, this uncertainty can be made more transparent by the presented approach identifying the weak points but also the strengths of interpolated maps (Atkinson and Lloyd, 1998; Rufino et al., 2005). Recapitulatory, the quantity of the analysed data allows the partitioning into a working and a validating dataset and bears a cross-validation. We achieved reliable results and evaluated only small deviations in our results using sophisticated high minimum probability values.

Even the refined analysis procedure (transforming raster data into regionalisation polygons and points, use of geostatistics, and the GIS overlay technique) contains acceptable deviations the results supply the first surface maps of the HMMV. They are used in Jerosch et al. (in press) in form of a predictive multi-parametric map after a GIS-based overlay of Beggiatoa, pogonophorans and uncovered mud. This map is used for area computations with respect to the source location of mud flows and pattern of biogeochemical habitats. Discussing the quality of surface maps is thus also tool to evaluate following continuative studies.
The maps developed in this study are considered as a guideline for further expeditions to the HMMV. For earlier habitat studies at the HMMV please refer to e.g. Gebruk et al. (2003) and Milkov et al. (1999, 2004).

Submarine mud volcanoes occur worldwide. Together with submarine asphalt volcanism sites (MacDonald et al., 2004) they provide the geochemical conditions (e.g. gas hydrates, methane release) creating habitats for chemosynthetic life (bacteria and tube worms). For example the Milano Mud Volcano of the Central Mediterranean Ridge (Huguen et al., 2005) and the Chapopote Asphalt Volcano in the Campeche Knolls, Gulf of Mexico, (Hovland et al., 2005; MacDonald et al., 2004) are potential study areas for similar evaluation procedures as conducted at the HMMV.

\section{Acknowledgements}

The authors thank all crew members and scientists onboard RV Polarstern and the Genavir team of ROV Victor6000 for their unremitting assistance. We are grateful to the Ifremer colleagues A.G. Allais, P. Siméoni, L. Méar for the technical support during the video mosaicing surveys. This study was performed in the framework of the R\&D-Programme GEOTECHNOLOGIEN funded by the German Ministry of Education and Research (BMBF) and German Research Foundation (DFG) as well as the AWI-Ifremer bilateral collaboration programme. This is publication no. GEOTECH-204.

\section{R E F E R E N C E S}

Akin, H., Siemens, H., 1988. Praktische Geostatistik. SpringerVerlag, Berlin-Heidelberg. 304 pp.

Allais, A.-G., Borgetto, M., Opderbecke, J., Pessel, N., Rigaud, V., 2004. Seabed video mosaicing with MATISSE: a technical overview and cruise results. Proceedings of 14th International Offshore and Polar Engineering Conference, ISOPE-2004, Toulon, France, May 23-28 2004, vol. 2, pp. 417-421.

Atkinson, P.M., Lloyd, C.D., 1998. Mapping precipitation in Switzerland with ordinary and indicator kriging. Journal of Geographic Information and Decision Analysis 2 (2), $65-76$.

Boetius, A., Ravenschlag, K., Schubert, C.J., Rickert, D., Widdel, F., Gieseke, A., Amann, R., Jørgensen, B.B., Witte, U., Pfannkuche, O., 2000. A marine microbial consortium apparently mediating anaerobic oxidation of methane. Nature 407, 623-626.

Boetius, A., Beier, V., Niemann, H., Müller, I., Heinrich, F., Feseker, T., 2004. Geomicrobiology of sediments and bottom waters of the Håkon Mosby Mud Volcano. In: Klages, M., Thiede, J., Foucher, J.-P. (Eds.), The Expedition ARK XIX/3 of the Research Vessel "Polarstern" in 2003. Reports on Polar and Marine Research, vol. 488 , pp. 190-199.

Damm, E., Budéus, G., 2003. Fate of vent-derived methane in seawater above the Håkon Mosby Mud Volcano (Norwegian Sea). Marine Chemistry 82, 1-11.

Davis, J.C., 2002. Statistics and Data Analysis in Geology, 3rd ed. John Wiley and Sons, New York. 638 pp.

De Beer, D., Sauter, E., Niemann, H., Witte, U., Schlüter, M., Boetius, A., in press. In situ fluxes and zonation of microbial activity in surface sediments of the Håkon Mosby Mud Volcano. Limnology and Oceanography. 
Dimitrov, L.I., 2002. Mud volcanoes - the most important pathway for degassing deeply buried sediments. Earth-Science Reviews 59, 49-76.

Eldholm, O., Sundvor, E., Vogt, P.R., Hjelstuen, B.O., Crane, K., Nilsen, A.K., Gladczenko, T.P., 1999. SW Barents Sea continental margin heat flow and Håkon Mosby Mud Volcano. Geo-Marine Letters 19, 29-37.

Fleischer, P., Orsi, T.H., Richardson, M.D., Anderson, A.L., 2001. Distribution of free gas in marine sediments: a global overview. Geo-Marine Letters 21, 103-122.

Gebruk, A.V., Krylova, E.M., Lein, A.Y., Vinogradov, G.M., Anderson, E., Pimenov, N.V., Cherkashev, G.A., Crane, K., 2003. Methane seep community of the Håkon Mosby Mud Volcano (the Norwegian Sea): composition and trophic aspects. Sarsia 88, 394-403.

Hjelstuen, B.O., Eldholm, O., Faleide, J.I., Vogt, P.R., 1999. Regional setting of Håkon Mosby Mud Volcano, SW Barents Sea margin. Geo-Marine Letters 19, 22-28.

Hovland, M., MacDonald, I.R., Rueslâtten, Johnsen, H.K., Naehr, T., Bohrmann, G., 2005. Chapopote Asphalt Volcano may have been generated by supercritical water. EOS 86 (42), 397-399.

Huguen, C., Mascle, J., Woodside, J., Zitter, T., Foucher, J.P., 2005. Mud volcanoes and mud domes of the Central Mediterranean Ridge: near-bottom and in situ observations. Deep-Sea Research. Part 1. Oceanographic Research Papers 52, 1011-1931.

Isaaks, E.H., Srivastava, R.M., 1992. An Introduction to Applied Geostatistics. Oxford University Press. 561 pp.

Jerosch, K., Schlüter, M., Foucher, J., Allais, A., Klages, M., Edy, C., in press. Spatial distribution of mud flows, chemoautotrophic communities, and biogeochemical habitats at Håkon Mosby Mud Volcano. Marine Geology.

Johnston, K., Ver Hoef, J.M., Krivoruchko, K., Lucas, N., 2001. Using ArcGIS Geostatistical Analyst. ESRI, Redlands, USA. 40 pp.

Jouffroy, J., Opderbecke, J., 2004. Underwater vehicle trajectory estimation using contracting PDE-based observers. American Control Conference (ACC 2004), Boston.

Journel, A.G., Huijbregts, C.J., 1978. Mining Geostatistics. Academic Press, London. 600 pp.

Klages, M., Thiede, J., Foucher, J.-P., 2004. The Expedition ARK XIX/ 3 of the Research Vessel "Polarstern" in 2003. Reports on Polar and Marine Research, vol. 488. 346 pp.

Kopf, A.J., 2002. Significance of mud volcanism. Reviews of Geophysics 40 (2), 1005. doi:10.1029/2000RG000093.

Levin, L.A., Ziebis, W., Mendoza, G.F., Growney, V.A., Tryon, M.D., Brown, K.M., Mahn, C., Gieskes, J.M., Rathburn, A.E., 2003. Spatial heterogeneity of macrofauna at northern California methane seeps: influence of sulphide concentration and fluid flow. Marine Ecology. Progress Series 265, 123-139.

Longhurst, A., 1998. Longhurst Areas: Ecological Geography of the Sea. Academic Press. 398 pp.

MacDonald, I.R., Bohrmann, G., Escobar, E., Abegg, F., Blanchon, P., Blinova, V., Brückmann, W., Drews, M., Eisenhauer, A., Han, X., Heeschen, K., Meier, F., Mortera, C., Naehr, T., Orcutt, B., Bernard, B., Brooks, J., De Faragó, M., 2004. Asphalt volcarism and chemosysthetic life in the Campeche Knolls, Gulf of Mexico. Science 304, 999-1002.

Matheron, G., 1963. Principles of geostatistics. Economic Geology $58,1246-1266$.

Milkov, A.V., 2000. Worldwide distribution of submarine mud volcanoes and associated gas hydrates. Marine Geology 167, 29-42.
Milkov, A.V., Vogt, P.R., Cherkashev, G., 1999. Sea-floor terrains of Håkon Mosby Mud Volcano as surveyed by deep-tow video and still photography. Geo-Marine Letters 19, 38-47.

Milkov, A.V., Vogt, P.R., Crane, K., Lein, A.Y., Sassen, R., Cherkashev, G.A., 2004. Geological, geochemical, and microbial processes at the hydrate-bearing Håkon Mosby mud volcano: a review. Chemical Geology 205, 347-366.

Odobez, J.M., Bouthémy, P., 1994. Robust multi-resolution estimation of parametric motion models applied to complex scenes. IRISA Intern Report. 788 pp.

Olea, R.A., 1999. Geostatistics for Engineers and Earth Scientists. Kluwer Academic Publishers, Boston. 328 pp.

Pimenov, N., Savvichev, A., Rusanov, I., Lein, A., Egorov, A., Gebruk, A., Moskalev, L., Vogt, P., 1999. Microbial processes of carbon cycle as the base of food chain of Håkon Mosby Mud Volcano benthic community. Geo-Marine Letters 19, 89-96.

Richmond, A., 2005. An alternative implementation of indicator kriging. Computers and Geosciences 28, 555-565.

Rivoirard, J., Simmonds, E.J., Foote, K., Fernandes, P., Bez, N., 2000. Geostatistics for Estimating Fish Abundance. Blackwell Science, UK. 216 pp.

Rufino, M.M., Maynou, F., Abelló, P., Gil de Sola, L., Yule, A.B., 2005. The effect of methodological options on geostatistical modelling of animal distribution: a case study with Liocarcinus depurator (Crustacea: Brachyura) trawl survey data. Fisheries Research 76, 252-265.

Sahling, H., Rickert, D., Lee, R.W., Linke, P., Suess, E., 2002. Macrofaunal community structure and sulfide flux at gas hydrate deposits from the Cascadia convergent margin, NE Pacific. Marine Ecology. Progress Series 231, 121-138.

Shi, J., Tomasi, C., 1994. Good features to track. Proceedings of the IEEE Conference on Computer Vision and Pattern Recognition (CVPR94), Seattle, WA, pp. 593-600.

Sibuet, M., Olu, K., 1998. Biogeography, biodiversity and fluid dependence of deep-sea cold-seep communities at active and passive margins. Deep-Sea Research. Part 2. Topical Studies in Oceanography 45, 517-567.

Smirnov, R.V., 2000. Two new species of pogonophoran from the Arctic mud volcano off northwestern Norway. Sarsia 85, 141-150.

Vincent, A.G., Jouffroy, J., Pessel, N., Opderbecke, J., Borgetto, M., Rigaud, V., 2003. Real-time georeferenced video mosaicing with the MATISSE system. Proceedings of the Oceans 2003 Marine Technology and Ocean Science Conference, MTS/IEEE OCEANS'03, San Diego, USA, September 22-26 2003, vol. 4, pp. 2319-2324.

Vogt, P.R., Gardner, J., Crane, K., 1999. The Norwegian-BarentsSvalbard (NBS) continental margin: introducing a natural laboratory of mass wasting, hydrates and ascent of sediment pore water and methane. Geo-Marine Letters 19, 2-21.

Webster, R., Oliver, M.A., 2001. Geostatistics for Environmental Scientists. John Wiley and Sons. Ltd, Chichester, New York. 286 pp.

Zabel, M., Hensen, C., Schlüter, M., 2000. Back to the ocean cycles: benthic fluxes and their distribution patterns. In: Schulz, H.D., Zabel, M. (Eds.), Marine Geochemistry. Springer-Verlag, BerlinHeidelberg. 455 pp. 